\title{
Hypoxia-inducible factor-1 $\alpha$ modulates the down-regulation of the homeodomain protein CDX2 in colorectal cancer
}

\author{
JIANBAO ZHENG, XUEJUN SUN, WEI WANG and SHAOYING LU \\ Department of General Surgery, First Affiliated Hospital of Medical College, \\ Xi'an Jiaotong University, 277 West Yanta Road, Xi'an 710061, P.R. China
}

Received November 10, 2009; Accepted January 25, 2010

DOI: $10.3892 /$ or_00000833

\begin{abstract}
Hypoxia-inducible factor- $1 \alpha(\mathrm{HIF}-1 \alpha)$ is the main active subunit of HIF-1, which promotes tumor cell survival and critical steps involved in tumor progression and aggressiveness. To clarify the possible involvement of the HIF- $1 \alpha$ subunit and homeodomain protein CDX2 in the development and progression of colorectal cancer (CRC), we examined in vivo the immunohistochemical expression of HIF- $1 \alpha$ and its topological correlation with CDX2 expression in colorectal adenocarcinoma. We then examined the in vitro effect of hypoxia mimicked by $\mathrm{CoCl}_{2}$ on mRNA and protein expression of HIF- $1 \alpha$ and CDX2 using two human colon cancer cell lines, SW480 and LS174T. In addition, hypoxiainduced changes in the mRNA expression of Snail were also analyzed. Of the 62 cases of CRC examined, 43 (69.4\%) and 39 (62.9\%) were positive for CDX2 and HIF-1 $\alpha$, respectively, such that their expression was correlated with differentiation grade, tumor stage and lymph node metastasis $\left(\chi^{2}\right.$ test, $\mathrm{p}<0.01)$. Furthermore, HIF-1 $\alpha$ expression observed in 10 of the $16(62.5 \%)$ poorly differentiated CRCs showed a topological correlation with loss of CDX2 expression. Realtime PCR and Western blotting demonstrated that CDX2 expression was decreased by $\mathrm{CoCl}_{2}(100 \mu \mathrm{M})$ in both SW480 and LS174T cells. mRNA and protein expression of HIF-1 $\alpha$ and mRNA expression of Snail was increased by hypoxia in both colon cancer cell lines. In conclusion, the present observations support that hypoxia-inducible factor- $1 \alpha$ induces down-regulation of CDX2 in colon carcinoma cells and that Snail may be involved in this regulation process. These findings suggest that hypoxia plays an important role in the malignant progression of CRC.
\end{abstract}

Correspondence to: Dr Xuejun Sun, Department of General Surgery, First Affiliated Hospital of Medical College, Xi'an Jiaotong University, 277 West Yanta Road, Xi'an 710061, P.R. China

E-mail: sxjsky@yahoo.cn

Key words: CDX2, HIF-1 $\alpha$, Snail, colorectal cancer

\section{Introduction}

Colorectal cancer (CRC) is one of the major malignancies worldwide and is the second leading cause of cancer death in the United States (1). Its severity is mainly attributable to the propensity of tumor cells to invade the stroma and eventually disseminate into metastases. The accumulation of irreversible genomic alterations plays a role in colorectal cancer progression (2). In addition, reversible changes induced by the microenvironment harboring malignant cells are also considered to be of prime importance for tumor cell invasion and metastatic dissemination (3). In the investigations described here, we pay close attention to CDX2 in this process. The caudal-related CDX2 homeobox gene encodes an intestinespecific transcription factor, which is crucial for development and homeostasis of the intestinal epithelium (4). The homoeotic function of CDX2 in defining intestinal identity is indicated by phenotypes resulting from CDX2 haploinsuffiency and gain of function in mouse models. In adult tissue, CDX2 inhibits cell growth and stimulates differentiation by activating intestine-specific genes, e.g., the enzyme sucrase isomaltase (5). Additionally, it acts as a tumor suppressor in the adult colon. Indeed, Bonhomme et al had shown that the reduced expression level of $\mathrm{CDX} 2$ in $\mathrm{CDX} 2 \%$ - facilitates tumor progression in a mouse model for sporadic colorectal cancer (6), which was later confirmed by Aoki et al in a model for familial adenomatous polyposis (7). This role is also supported by the observation that expression of CDX2 decreases in human $\mathrm{CRC}$ in relation to tumor grade and in chemicallyinduced rat tumors (8-10). Altered expression of homeobox genes has been reported in several cancers, leading to changes in cell migration and spreading. Histopathological analyses have reported that CDX2 expression is low in invasive cells of colorectal cancer, which localize at the tumor/stroma interface, but are restored in metastases at the level corresponding to primary tumors (11). Yet, the CDX2 gene is rarely mutated in CRCs (12), suggesting that its altered expression in cancer cells depends on negative regulatory pathway(s). Supporting studies have provided evidence for such a decline in CDX2, but the detailed molecular mechanism remains unknown. Indeed, many other influencing factors could be contributing to this decline.

The search for factors affecting the progression and behavior of tumors has revealed the importance of the microenvironment surrounding the tumor cells. A major feature of 
solid tumors is hypoxia, the decreased availability of oxygen, increasing patient treatment resistance and favoring tumor progression. Clinical studies have brought forth the hypothesis that tumor hypoxia is an important microenvironmental determinant for tumor cell dissemination. Hypoxia is known to induce hypoxia-inducible factor- $1 \alpha(\mathrm{HIF}-1 \alpha)$, which binds to the hypoxia-response elements (HRE) of various target genes and activates their transcription, controlling glucose transport, angiogenesis, erythropoiesis, and vasomotor regulation, and potentially increasing the survival of tumor cells $(13,14)$. A subsequent study has demonstrated that hypoxic cells indeed also localize at hypoxic necrotic/viable tumor margins and tumor/stromal margins. In colonic adenocarcinoma, cancer cells at the leading edge of an infiltrating carcinoma manifest the most intense HIF-1 $\alpha$ immunostaining (15). A comparison of tumor and flanking normal tissue allows the patient to serve as his own control and supports the hypothesis that HIF-1 $\alpha$ overexpression is associated with angiogenesis, invasion, and metastasis $(16,17)$.

However, little is known about hypoxic status in vivo and its functional relationship with the expression of CDX2 in CRCs. Therefore, we first examined the expression and localization of HIF-1 $\alpha$ immunohistochemically in relation to CDX2 in CRCs. Based on the topological correlation between the two molecules, we hypothesized that hypoxia may reduce the CDX2 expression that accelerates CRC progression.

More recently, an experimental study revealed that the transcription repressor Snail associated with epithelial to mesenchymal transition (EMT) is stimulated in migrating Caco2/TC7 cells and could down-regulate CDX2 (17). Indeed, hypoxia has also been implicated in up-regulating Snail expression because the Snail promoter had two potential HRE (Hypoxia-Response Elements) sites (18). Furthermore, hypoxia can act in synergy to control the up-regulated expression of Snail by augmenting Notch signaling in various tumor cell lines, including colorectal cancer (19).

In this study, we examined the effect of hypoxia induced by Cobalt chloride $\left(\mathrm{CoCl}_{2}\right)$ on the change in expression of CDX2 at the mRNA and protein levels in colorectal cancer cell lines. $\mathrm{CoCl}_{2}$-induced changes in the mRNA expression of Snail were also analyzed.

\section{Materials and methods}

Sample preparation. Formalin-fixed and paraffin-embedded samples were obtained from surgical resection of colorectal cancers at the First Affiliated Hospital, Medical College, Xi'an Jiaotong University. No patient had received preoperative chemotherapy or radiotherapy. Overall, 62 patients (male, 29; female, 33) with CRC were enrolled in the study. The mean age of the patients was 60 years (range, 29-89). All 62 specimens were evaluated with respect to differentiation (well, 28; moderate, 18; and poor, 16) and tumor stage according to Dukes' criteria. Each tissue was used with the approval of the Ethics Committee of the First Affiliated Hospital, Medical College, Xi'an Jiaotong University, after obtaining written informed consent from the patient.

Immunohistochemistry staining. Three- to four-micrometer sections from paraffin-embedded tissue (microarrays) were used for immunohistochemistry. Slides were deparaffinized in fresh xylene and rehydrated through sequential graded ethanols. Antigen retrieval was performed by citrate buffer incubation (10 mmol/l, $\mathrm{pH}$ 6.0) using a microwave pressure cooker for $20 \mathrm{~min}$. Slides were cooled for $20 \mathrm{~min}$, incubated for 5 min with $3 \%$ hydrogen peroxide, washed in phosphatebuffered saline-0.1\% Triton X-100 (pH 7.6), blocked for $20 \mathrm{~min}$ in $20 \%$ normal goat serum, and incubated in an appropriate antibody dilution for CDX2 (1:400, mouse monoclonal; Biogenex, San Ramon, CA) or HIF-1 $\alpha$ (1:400, rabbit polyclonal; Boster, Wu Han, China) overnight at $4^{\circ} \mathrm{C}$. The next day, slides were washed in phosphate-buffered saline$0.1 \%$ Triton X-100 and incubated for $30 \mathrm{~min}$ in a 1:200 dilution of biotinylated anti-mouse or anti-rabbit secondary antibody. The ABC Elite kit (Boster) with 3,3'-diaminobenzidine development was used to visualize antibody binding, and slides were subsequently counterstained with hematoxylin. Negative controls were included by replacement of the primary antibody with phosphate-buffered saline. The evaluation of immunostaining of CDX2 and HIF- $1 \alpha$ genes were made simultaneously by two independent observers in a blinded manner. The staining was scored using four grades according to staining intensity: $0,1+, 2+$, and $3+$. The genepositive cells were also scored into four categories: $0(0 \%), 1$ $(1-33 \%), 2(34-66 \%)$, and $3(67-100 \%)$. For CDX2, completely negative scores were rare. The sum of the intensity and percentage scores was used as the final gene staining score, defined as: 0-4, negative; 5-6, positive.

Colonic cancer cell lines and treatment. The human colonic cancer cell lines SW480 and LS174T were purchased from ATCC. The two human colonic cancer cell lines were cultured under standard conditions in Dulbecco's modified Eagle's medium containing $10 \%$ fetal bovine serum and $200 \mathrm{U} / \mathrm{ml}$ penicillin-streptomycin (Invitrogen, Cergy Pontoise, France). Incubation was carried out at $37^{\circ} \mathrm{C}$ under $5 \% \mathrm{CO}_{2}$ in air. Then the cells were seeded at a density of $1 \times 10^{5}$ cells per well in 6-well plates and treated with $\mathrm{CoCl}_{2}$ (100, 150, $200 \mu \mathrm{M}$, Sigma-Aldrich, St. Louis, MO) on the second day for 24,36 and $48 \mathrm{~h}$. The cells were then harvested for total RNA and protein extraction.

Cell viability assay. Effects of $\mathrm{CoCl}_{2}$ on the viability of SW480 and LS174T cells were detected using a cell viability assay. Cells were plated in a 96-well plate $\left(1 \times 10^{4}\right.$ cells/well $)$ for $24 \mathrm{~h}$, and then treated with different concentrations of $\mathrm{CoCl}_{2}(100,150,200 \mu \mathrm{M})$ for $24,36,48 \mathrm{~h}$. Tetrazolium dye, 3-(4,5-dimethylthiazol-2)-2,5-diphenyl-2H-tetrazolium bromide (MTT, Sigma; $5 \mathrm{mg} / \mathrm{ml}$ in PBS) was added to the medium for $4 \mathrm{~h}$ and measured by spectrophotometry after $15 \mathrm{~min}$ at room temperature. Optical density (OD), which reflects the viable cell population in each well, was determined, and cell viability was evaluated by measuring the intensity of the blue color (OD at $492 \mathrm{~nm}$ ) using a multiwell reader (Spectracount-Packard Canberra, USA).

RNA extraction and cDNA synthesis. Total RNA was extracted using the TRIzol reagent (Invitrogen, Carlsbad, CA, USA) according to the manufacturer's guidelines. To avoid possible genomic DNA contamination, all RNA samples 
were treated with RNase-free DNase (Promega, Madison, WI, USA) and stored at $-70^{\circ} \mathrm{C}$. RNA concentration was determined spectrophotometrically, and RNA quality was checked by agarose gel electrophoresis. Total RNA $(1.0 \mu \mathrm{g})$ was reverse-transcribed using a SuperScript III first-strand synthesis system for RT-PCR kit (Invitrogen) according to the manufacturer's protocol.

Real-time polymerase chain reaction. Real-time polymerase chain reaction (qPCR) was performed with the following primers for human CDX2 (sense, 5'-GAACCTGTGCGAG TGGATG-3' and antisense, 5'-GGTGATGTAGCGACTG TAGTGAA-3'), HIF-1 $\alpha$ (sense, 5'-CCCAGATTCAGGATC AGACAC-3' and antisense, 5'-TTGGGATATAGGGAGC TAACATC-3'), Snail (sense, 5'-TCTAGGCCCTGGCTGC TACAA-3' and antisense, 5'-ACATCTGAGTGGGTCTGG AGGTG-3'), and GAPDH (sense, 5'-GCACCGTCAAGG CTGAGAAC-3' and antisense 5'-TGGTGAAGACGCCA GTGGA-3'). All primers were obtained from Sangog Ltd (Shanghai, China). qPCR was performed on an iQ5 RealTime PCR Detection System (Bio-Rad, CA, USA) in 96well plates. The reaction was performed in a final volume of $20 \mu 1$. All qPCR mixtures contained $2 \mu 1$ of cDNA template (corresponding to $\sim 40 \mathrm{ng}$ of retro-transcribed total RNA), each primer $(20 \mathrm{nmol} / \mathrm{l})$ and 2 X SYBR-Green PCR Master Mixtures (10 $\mu \mathrm{l}$; Applied Biosystems). Cycle conditions were as follows: after an initial 2 -min hold at $50^{\circ} \mathrm{C}$ to allow AmpErase-UNG activity and $10 \mathrm{~min}$ at $95^{\circ} \mathrm{C}$, the samples were cycled 40 times at $95^{\circ} \mathrm{C}$ for $15 \mathrm{sec}$ and $61^{\circ} \mathrm{C}$ for $1 \mathrm{~min}$. The value of threshold cycle $(\mathrm{Ct})$ for each reaction was recorded and analyzed with a Bio-Rad iQ5 Real-Time Detection System Software by using the $2^{-\Delta \Delta C t}$ method for relative quantitation.

Western blot analysis. For Western blot analysis, $1 \times 10^{6}$ cells were scraped off, washed once with ice-cold PBS, resuspended in 100-200 $\mu 1$ lysis buffer (50 mM Tris, $150 \mathrm{mM}$ $\mathrm{NaCl}, 5 \mathrm{mM}$ EDTA, 5 mM EGTA, 1\% SDS, pH 7.5), and then ultrasonicated on ice until the solution became clear. The total protein concentration was measured using the classical Bradford method. Samples were heated at $100^{\circ} \mathrm{C}$ for 5 min with 2X SDS loading buffer and briefly cooled on ice. As such, $80 \mu \mathrm{g}$ total protein from each sample were subjected to 8 or $10 \%$ SDS-PAGE to detect HIF-1 $\alpha(120 \mathrm{kDa})$ and CDX2 (38 kDa), $\beta$-actin (43 kDa), respectively. Protein bands were then transferred to PVDF membrane in $25 \mathrm{mM}$ Tris (pH 8.5), $200 \mathrm{mM}$ glycerin, and $20 \%$ methanol at $100 \mathrm{~V}$ for $2 \mathrm{~h}$. Proteins were detected using rabbit polyclonal antibody to HIF-1 $\alpha$ (sc-10790, 1:1000 dilution, Santa Cruz, USA), mouse monoclonal antibody CDX2 (AM392-M, 1:500 dilution, BioGenex, USA) and mouse monoclonal antibody to $\beta$-actin (sc-47778, 1:1000 dilution, Santa Cruz) was used as a loading control. Membranes were incubated with primary antibodies overnight at $4^{\circ} \mathrm{C}$ after blocking in $5 \%$ non-fat milk for $1 \mathrm{~h}$ at room temperature, and were then incubated with horseradish peroxidase-conjugated goat anti-rabbit or goat anti-mouse IgG (BeiJing ZhongShan Goldbridge Biotechnology Co., China). NBT/BCIP chemiluminescence (Amresco, USA) was used to detect immunopositive protein bands.
Statistical analyses. All statistical analyses were performed using the SPSS 13.0 software package for Windows. To evaluate whether the frequency of cells with elevated levels of CDX2 and HIF-1 $\alpha$ expression increased during colorectal carcinogenesis, we performed a $\chi^{2}$ test for trends, grouping the results as differentiation, lymph node metastasis, and clinical stage (Dukes' criteria A-D). No cases were excluded from statistical analysis. Experimental in vitro data are presented as means \pm SEM. Comparisons were subjected to one-way analysis of variance (ANOVA) followed by the Student's t-test. $\mathrm{P}<0.05$ was considered to be statistically significant.

\section{Results}

Immunohistochemistry for CDX2. Normal colonic mucosa showed moderate to strong nuclear expression of CDX2 proteins in most glandular epithelial cells (Fig. 1I). The expression of CDX2 in tumor cells was clearly marked on the nucleus of colorectal tumor cells. Interestingly, the expression of CDX2 protein was detected in $43(69.4 \%)$ of 62 colorectal cancers (Table I). Based on differentiation grade, CDX2 was expressed in $92.9 \%(26 / 28), 66.7 \%$ (12/18) and $31.3 \%(5 / 16)$ of well, moderately and poorly differentiated $\mathrm{CRC}$, respectively. In this classification, the proportion of CDX2-positive cases was significantly lower in the poorly differentiated type $\left(\chi^{2}\right.$ test, $\left.\mathrm{p}<0.01\right)$. Clinically, CDX2 expression was seen in $16(94.1 \%)$ of 17 cases corresponding to stage A, $16(80 \%)$ of 20 corresponding to stage B, 9 (52.9\%) of 17 corresponding to stage C, and 2 (25.0\%) of 8 corresponding to stage D. Statistically, CDX2 protein expression was significantly related to clinical stage $\left(\chi^{2}\right.$ test, $\mathrm{p}<0.01)$. In addition, the CDX2 expression was detected in $11(44.0 \%)$ of 25 cases with lymph node metastasis, and there was a significant statistical difference between loss of CDX2 expression and lymph node metastasis $\left(\chi^{2}\right.$ test, $\mathrm{p}<0.01$ ) (Table I).

Immunohistochemistry for HIF-1a. Specific immunoreactivity for HIF-1 $\alpha$ was not observed in normal colorectal mucosa (Fig. 1E). The expression of HIF-1 $\alpha$ protein was observed mainly in the cytoplasm of tumor cells, but nuclear staining was sporadically observed only in poorly differentiated colorectal tumor cells (Fig. 1H). HIF-1 $\alpha$ was predominantly expressed in cells that were located at the invading edge of the tumors and adjacent to the necrotic areas in colorectal cancers (Fig. 2). Among colorectal carcinoma tissue samples, the positive rate of HIF-1 $\alpha$ expression was $62.9 \%$ (39 of 62) (Table I). HIF-1 $\alpha$ was expressed differently between well, moderately and poorly differentiated CRC. The expression of HIF- $1 \alpha$ was $46.4 \%$ (13/28), $72.2 \%(13 / 18)$ and $81.3 \%(13 / 16)$, respectively. A significant difference was found between the well, moderately and poorly differentiated CRC ( $\chi^{2}$ test, $\mathrm{P}<0.05$ ). Simultaneously, HIF-1 $\alpha$ expression was seen in $35.3,60.0,76.5$, and $100 \%$ of cases corresponding to clinical stages A-D, respectively. Statistically, HIF-1 $\alpha$ protein expression was also significantly related to clinical stage $\left(\chi^{2}\right.$ test, $\left.\mathrm{p}<0.01\right)$. Furthermore, HIF- $1 \alpha$ expression was positive in $21(84.0 \%)$ of 25 cases with lymph node metastasis, and there was a significant statistical difference $\left(\chi^{2}\right.$ test, $\left.\mathrm{p}<0.01\right)$ (Table I). 

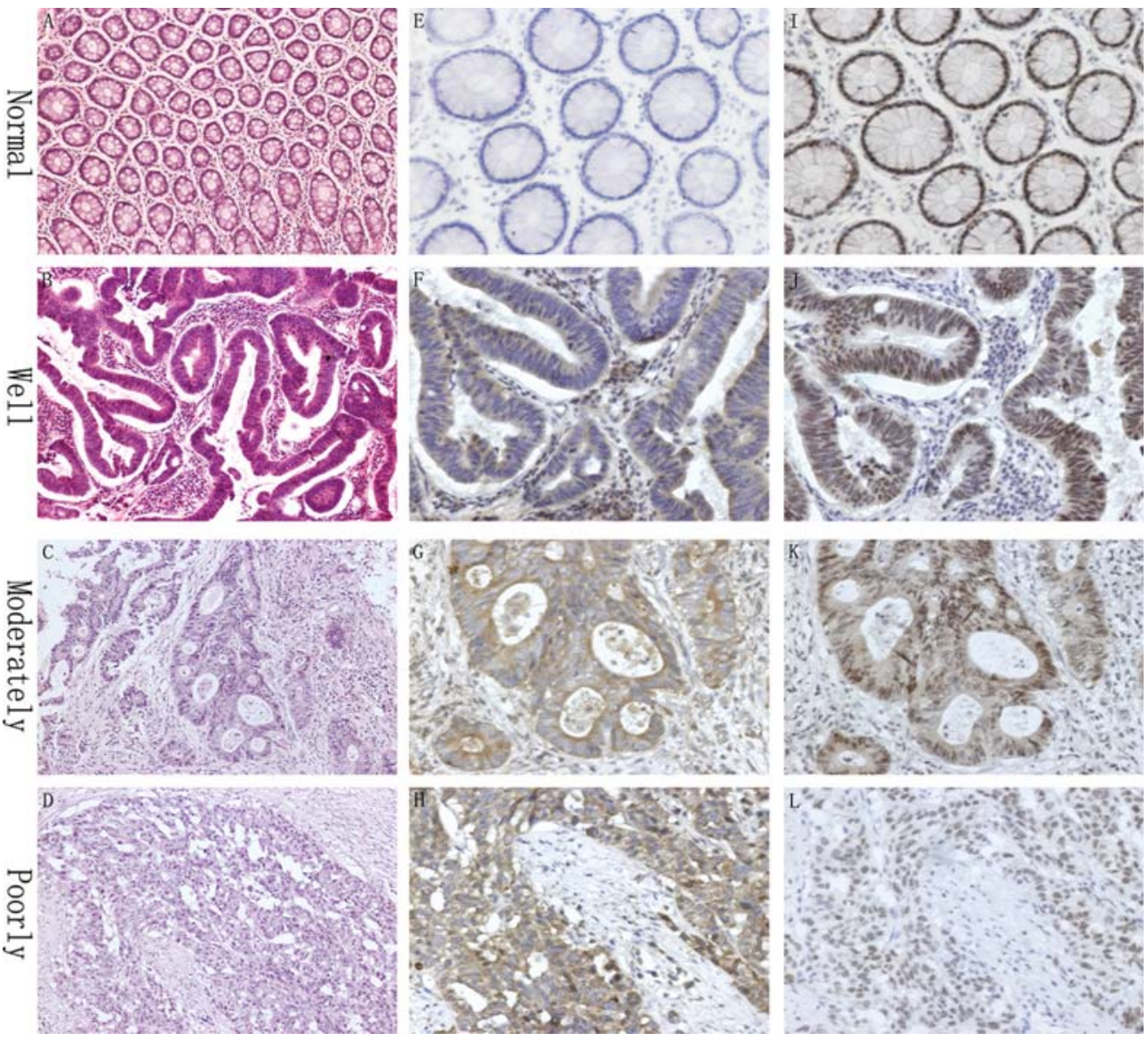

Figure 1. Photographs of four groups defined by immunohistochemical staining for HIF-1 $\alpha$ and CDX2 in normally, well, moderately and poorly differentiated CRC. No HIF-1 $\alpha$ immunoreactivity was detected in normal colorectal mucosa (E). Well-differentiated colorectal adenocarcinoma exhibited weak cytoplasm staining for HIF-1 $\alpha$ protein (F). By contrast, moderately to strong HIF-1 $\alpha$ immunoreactivity was detected in the cytoplasm of tumor cells in moderately or poorly differentiated colorectal adenocarcinoma and was also detected in the nucleus of partial poorly-differentiated colorectal cancer ( $\mathrm{G}$ and $\mathrm{H})$. Normal colonic mucosa and well-differentiated colorectal adenocarcinoma exhibited strong nuclear staining for CDX2 protein (I and J), moderately-differentiated colorectal adenocarcinoma displayed moderate to high immunoreactivity in the nucleus of cancer cells $(\mathrm{K})$, and poorly-differentiated colon cancer showed relative weak CDX2 immunostaining (L). A-D, H\&E staining; original magnification, x200. E-H, HIF-1 $\alpha$; I-L, CDX2; original magnification, x400.

Table I. Immunohistochemical expression of HIF-1 $\alpha$ and CDX2 in colorectal carcinoma.

\begin{tabular}{|c|c|c|c|c|c|}
\hline \multirow[b]{2}{*}{ Parameters } & \multirow[b]{2}{*}{ Total } & \multicolumn{2}{|c|}{ HIF-1 $\alpha$} & \multicolumn{2}{|c|}{ CDX2 } \\
\hline & & + & Positive cases (\%) & + & Positive cases $(\%)$ \\
\hline \multicolumn{6}{|l|}{ Differentiation } \\
\hline Well & 28 & 13 & $46.4^{\mathrm{a}}$ & 26 & $92.9^{\mathrm{d}}$ \\
\hline Moderately & 18 & 13 & 72.2 & 12 & 66.7 \\
\hline Poorly & 16 & 13 & 81.3 & 5 & 31.3 \\
\hline \multicolumn{6}{|l|}{$\mathrm{L} / \mathrm{N}$ metastasis } \\
\hline Positive & 25 & 21 & $84.0^{\mathrm{b}}$ & 11 & $44.0^{\mathrm{e}}$ \\
\hline Negative & 37 & 18 & 48.6 & 32 & 86.5 \\
\hline \multicolumn{6}{|l|}{ Stage } \\
\hline A & 17 & 6 & $35.3^{\mathrm{c}}$ & 16 & $94.1^{\mathrm{f}}$ \\
\hline $\mathrm{B}$ & 20 & 12 & 60.0 & 16 & 80.0 \\
\hline $\mathrm{C}$ & 17 & 13 & 76.5 & 9 & 52.9 \\
\hline $\mathrm{D}$ & 8 & 8 & 100.0 & 2 & 25.0 \\
\hline Total & 62 & 39 & 62.9 & 43 & 69.4 \\
\hline
\end{tabular}

${ }^{\mathrm{a}} \chi^{2}$ test $=6.2372 \mathrm{p}<0.05 ;{ }^{\mathrm{b}} \chi^{2}=7.9901 \mathrm{p}<0.01 ;{ }^{\mathrm{c}} \chi^{2}=11.6808 \mathrm{p}<0.01 ;{ }^{\mathrm{d}} \chi^{2}=18.2652 \mathrm{p}<0.01 ;{ }^{\mathrm{e}} \chi^{2}=12.6711 \mathrm{p}<0.01 ;{ }^{\mathrm{f}} \chi^{2}=15.5248 \mathrm{p}<0.01$. 

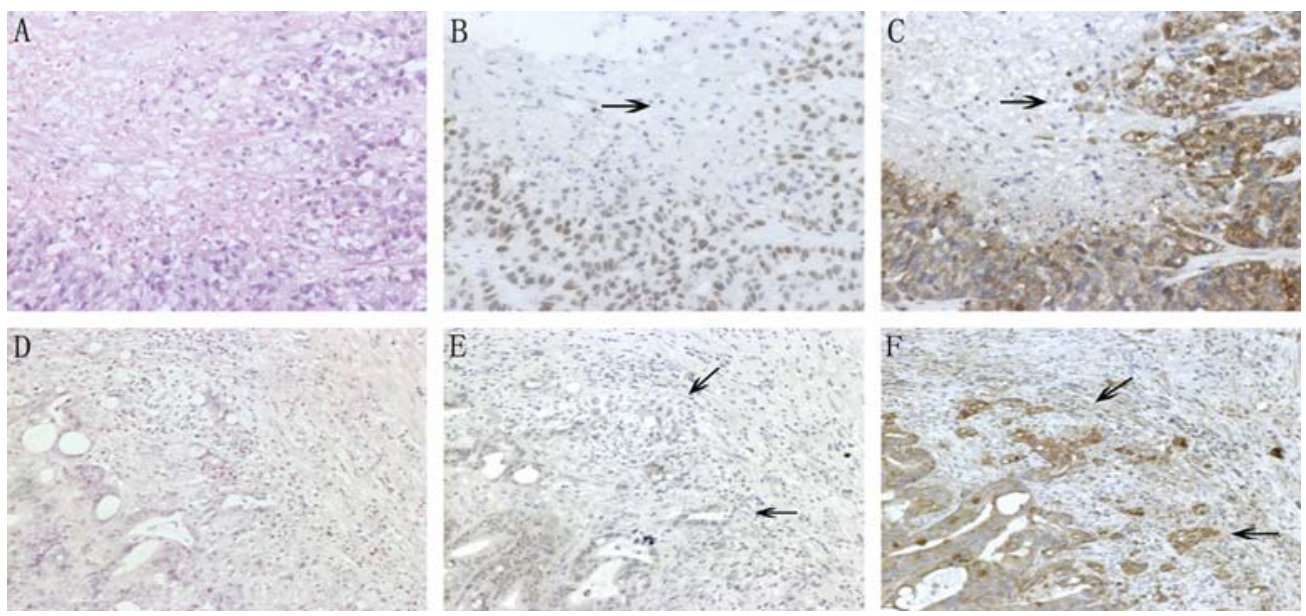

Figure 2. Topological correlation between HIF-1 $\alpha$ and CDX2. The immunohistochemical staining of HIF-1 $\alpha$ was enhanced adjacent to the necrotic areas or at the invading edge of the tumors in colorectal cancers ( $\mathrm{C}$ and $\mathrm{F}$ ). In serial sections for the immunolocalizations of HIF-1 $\alpha$ and CDX2, the tumor cells with cytoplasmic expression of HIF-1 $\alpha$ (C and F arrows) are associated with reduced or absent CDX2 expression (B and E arrows). A and D, H\&E staining. A-C, original magnification, $\mathrm{x} 400$; D-F, original magnification, $\mathrm{x} 200$.

A

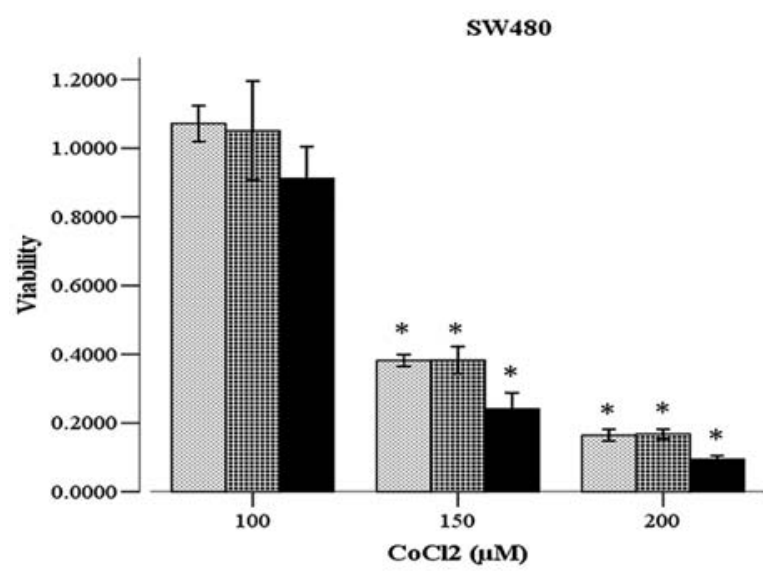

B

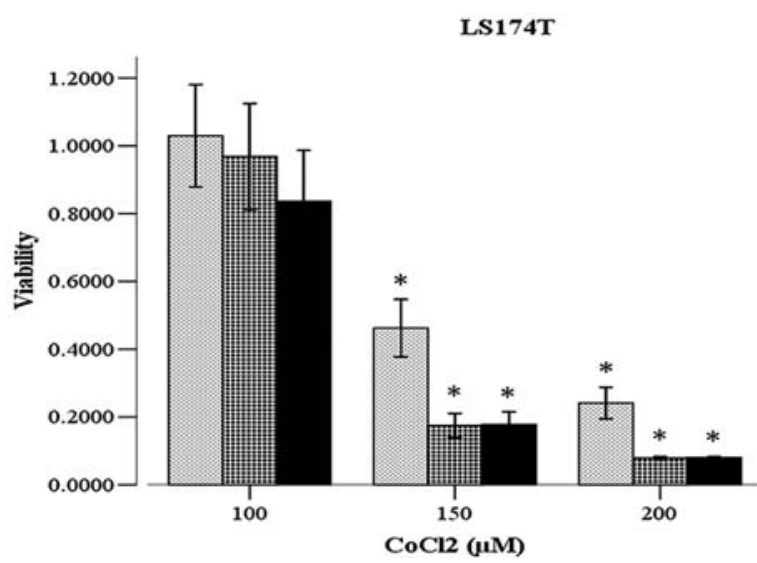

Figure 3. Effect of Cobalt chloride on proliferation of SW480 and LS174T cells in vitro. SW480 and LS174T cells were treated with various concentrations of $\mathrm{CoCl}_{2}$ for 24, 36, and $48 \mathrm{~h}$. Dose-dependent suppression of cell viability (relative to control) was determined by an MTT assay. Five samples were analyzed in each group, and the results are presented as means \pm SEM * $\mathrm{p}<0.01$, vs. DMSO $(0 \mu \mathrm{M})$ control.
Topological correlation between CDX2 and HIF-1a. Closer observation of the immunoreactivity for CDX2 and HIF-1 $\alpha$ using serial sections disclosed that the tumor cells with HIF- $1 \alpha$ expression were associated with reduced expression of CDX2. Such reduced expression of CDX2 along with HIF- $1 \alpha$ expression was observed in 10 of the 16 poorly differentiated CRCs $(62.5 \%)$, especially at the in the vicinity of the necrotic area in colorectal cancers (Fig. 2A-C) or invading edge of the tumors (Fig. 2D-F).

Effect of $\mathrm{CoCl}_{2}$ on the growth of SW480 and LS174T cells in vitro. The SW480 and LS174T cells were treated with different concentrations of $\mathrm{CoCl}_{2}(100,150,200 \mu \mathrm{M})$ for various times $(24,36,48 \mathrm{~h})$, and cell viability was determined using an MTT assay. $\mathrm{CoCl}_{2}$ inhibited the growth of the colon cancer cell lines in a dose-dependent manner (Fig. 3). Cell viability (relative to control) was remarkably suppressed after treatment with 150 and $200 \mu \mathrm{M} \mathrm{CoCl}_{2}$ for 24,36 , and $48 \mathrm{~h}(\mathrm{p}<0.01)$. Thus, we selected the lower concentration $(100 \mu \mathrm{M})$ of $\mathrm{CoCl}_{2}$ for mimicking hypoxia.

mRNA expression of CDX2, HIF-1 $\alpha$ and Snail in colon cancer cell lines under mimicking hypoxia. To clarify whether mimicking hypoxic conditions decrease CDX2 mRNA expression and address the possible mechanism involved in the hypoxia-induced change in CDX2 expression, we examined the mRNA expression of CDX2, HIF-1 $\alpha$ and Snail using real-time RT-PCR. mRNA expression of HIF-1 $\alpha$, Snail, CDX2 and GAPDH were detected in cultured cells in both normoxia and hypoxia mimicked by $\mathrm{CoCl}_{2}(100 \mu \mathrm{M})$ at 24, 36, and $48 \mathrm{~h}$. Real-time RT-PCR results showed that $\mathrm{CoCl}_{2}$ induces mRNA expression of HIF-1 $\alpha$, Snail in a timedependent manner. The expression peaked at $24 \mathrm{~h}$ and remained elevated at $48 \mathrm{~h}$ (Tables II and III). Simultaneously, mRNA expression of CDX2 was decreased compared to normoxic conditions.

Protein expression of HIF-1a and CDX2. Specific bands for HIF- $1 \alpha(120 \mathrm{kDa})$ and CDX2 (38 kDa) under normoxia and 
Table II. Expression of CDX2, Snail and HIF-1 $\alpha$ mRNA in human SW480 cells.

\begin{tabular}{lcrrr}
\hline & & & \multicolumn{2}{c}{$\mathrm{CoCl}_{2}(100 \mu \mathrm{M})$} \\
\cline { 3 - 5 } Groups & Normoxia & $24 \mathrm{~h}$ & $36 \mathrm{~h}$ & $48 \mathrm{~h}$ \\
\hline CDX2 & $1.8827 \pm 1.1341$ & $1.3202 \pm 0.5978$ & $0.9370 \pm 0.1148$ & $0.6344 \pm 0.1779^{\mathrm{a}}$ \\
Snail & $0.3152 \pm 0.2267$ & $7.014 \pm 0.9856^{\mathrm{b}}$ & $6.2121 \pm 0.3319^{\mathrm{b}}$ & $4.1444 \pm 0.6216^{\mathrm{b}}$ \\
HIF-1 $\alpha$ & $1.1558 \pm 0.2699$ & $8.5085 \pm 1.3498^{\mathrm{b}}$ & $6.8071 \pm 0.4388^{\mathrm{b}}$ & $3.0078 \pm 0.4972^{\mathrm{a}}$ \\
\hline
\end{tabular}

Data are expressed as $2^{-\Delta \Lambda C T}$ (mean $\left.\pm \mathrm{SEM}\right) .{ }^{\mathrm{a}} \mathrm{p}<0.05$ vs. normoxia; ${ }^{\mathrm{b}} \mathrm{p}<0.01$ vs. normoxia.

Table III. Expression of CDX2, Snail and HIF-1 $\alpha$ mRNA in human LS174T cells.

\begin{tabular}{llccc}
\hline & & & $\mathrm{CoCl}_{2}(100 \mu \mathrm{M})$ \\
\cline { 3 - 5 } Groups & Normoxia & $24 \mathrm{~h}$ & $36 \mathrm{~h}$ & $48 \mathrm{~h}$ \\
\hline CDX2 & $0.9877 \pm 0.0213$ & $0.731 \pm 0.1810$ & $0.5483 \pm 0.0766^{\mathrm{a}}$ & $0.3272 \pm 0.2036^{\mathrm{a}}$ \\
Snail & $0.6136 \pm 0.2386$ & $4.6113 \pm 0.4778^{\mathrm{b}}$ & $3.4577 \pm 0.1688^{\mathrm{b}}$ & $2.3567 \pm 0.5650^{\mathrm{b}}$ \\
HIF-1 $\alpha$ & $1.1567 \pm 0.7388$ & $3.8885 \pm 2.3015^{\mathrm{a}}$ & $2.7704 \pm 0.2189^{\mathrm{a}}$ & $1.6741 \pm 0.5150$ \\
\hline
\end{tabular}

Data are expressed as $2^{-\triangle \Lambda C T}$ (mean \pm SEM). ${ }^{a} \mathrm{p}<0.05$ vs. normoxia; ${ }^{b} \mathrm{p}<0.01$ vs. normoxia.

hypoxia were detected by Western blotting in both SW480 and LS174T (Fig. 4A and B). B-actin was expressed at $43 \mathrm{kDa}$ in all samples. In colon cancer cell lines, treatment with $100 \mu \mathrm{M} \mathrm{CoCl}_{2}$ induced protein expression of HIF-1 $\alpha$ in a time-dependent manner. The pattern of expression had two phases, a peak at $24 \mathrm{~h}$ of treatment remained elevated until $48 \mathrm{~h}$. The expression of CDX2 was decreased under hypoxia compared with those for normoxia (Fig. 4C).

\section{Discussion}

The CDX2 homeobox gene, one of a family of transcription factors, plays a critical role in the early differentiation, maintenance, and proliferation of intestinal epithelial cells. It has been suggested that CDX2 is a master 'control gene' for intestinal epithelial differentiation and proliferation (8). Previous observations have supported that CDX2 protein may be a potent suppressor of tumorigenic growth and that CDX2 inactivation may contribute to the tumorigenesis of CRC $(11,20)$. In the present study, we analyzed expression patterns of CDX2 protein in primary CRCs. We found CDX2 expression in $43(69.4 \%)$ of 62 CRCs. Nuclear CDX2 expression was very strong in the tumor cells of well-differentiated cancer, but relative decreased in poorly differentiated carcinomas. In addition, the loss of CDX2 expression was statistically closely associated with differentiation grade, higher clinical stage and lymph node metastasis. Although the number of cases analyzed in this study is not sufficient to draw any definitive conclusion, these results suggest that loss of CDX2 expression is associated with progression to more advanced stages of colorectal tumorigenesis. Our data are consistent with previous reports in which expression of CDX2 showed significant correlation with tumor grade and stage of CRC $(10,21,22)$. Thus, CDX2 seems to be a highly valuable marker that is closely associated with differentiation and dissemination of CRC cells.

Recently, a study experimentally demonstrated that the expression of CDX2 in CRC cells was adaptable and strongly dependent on the tumor microenvironment. This might be particularly important in the process of metastatic dissemination because the gene is transiently down-regulated in invasive cells (23). Thus, we focused on hypoxia, a major feature of solid tumors. In colonic adenocarcinoma, HIF-1 $\alpha$ overexpression is associated with angiogenesis, invasion, and metastasis (15). We found HIF-1 $\alpha$ expression in 39 (62.9\%) of 62 CRCs. In addition, our study showed that HIF- $1 \alpha$ expression was topologically correlated with the loss of CDX2 expression. In our study, the expression of HIF-1 $\alpha$ was mainly in the cytoplasm of tumor cells and located at invading edge of the tumors and surrounding areas of neovascularization in colorectal cancers. Such localization of HIF- $1 \alpha$ seems to be consistent with reports showing that the tumor cells at these sites are under hypoxia (16). The expression and localization of HIF-1 $\alpha$ was reported to be well correlated with tissue hypoxia (24). Here, our in vivo observation of an inverse correlation between HIF-1 $\alpha$ and CDX2 suggests that the expression of HIF-1 $\alpha$ along with down-regulation of CDX2 might have occurred under hypoxia in tumor progression in colorectal cancer.

Based on the above findings, we hypothesized that hypoxia may directly or indirectly down-regulate the expression of CDX2, resulting in the tumor progression observed in CRC. 


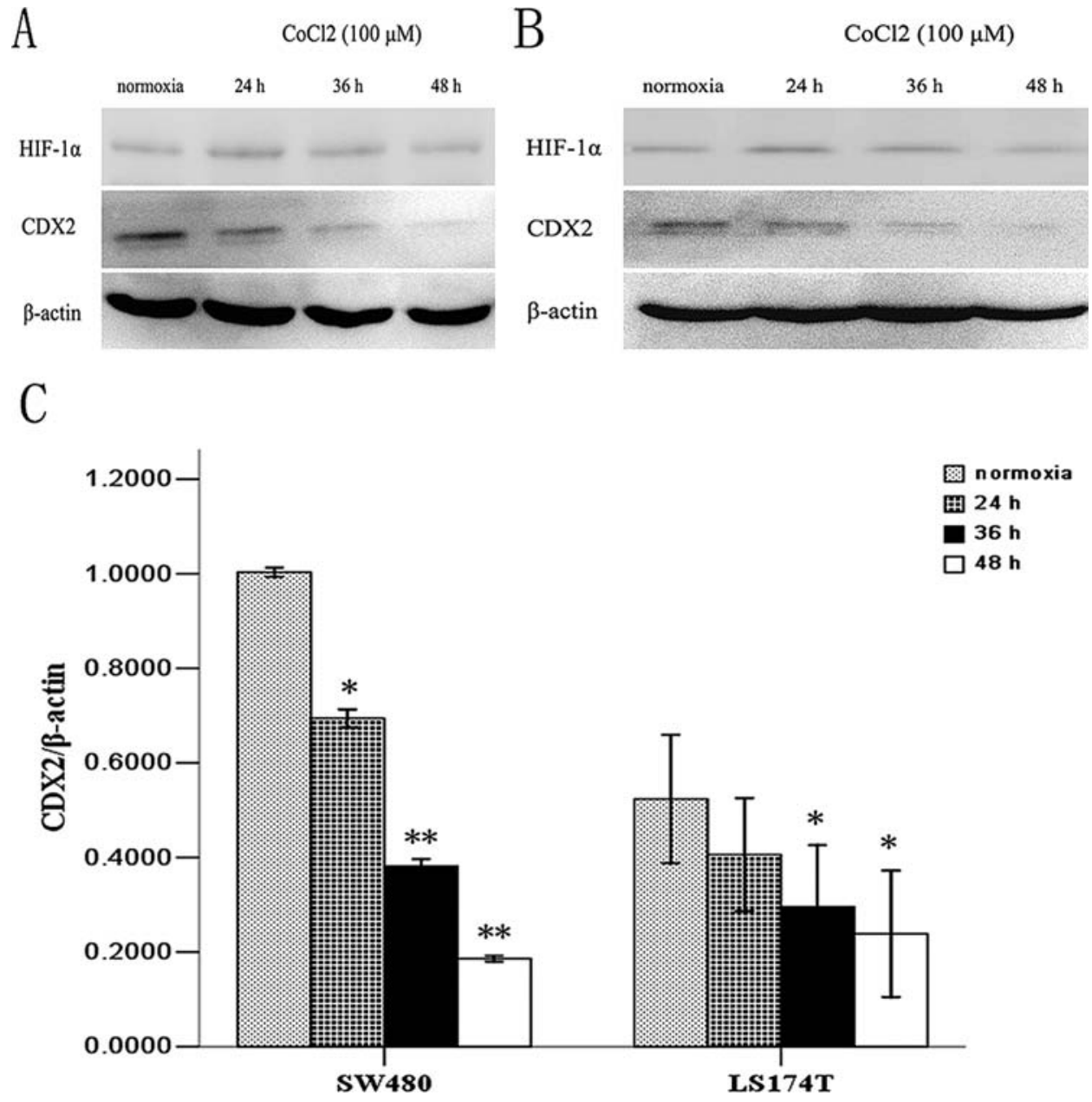

Figure 4. Western blot analysis showing the effect of hypoxia mimicked by $\mathrm{CoCl}_{2}$ on $\mathrm{HIF}-1 \alpha$ and CDX2 proteins in the two human colon cancer cell lines SW480 (A) and LS174T (B). Specific bands for HIF-1 $\alpha$ and CDX2 were detected, and CDX2 was significantly decreased in SW480 and LS174T under $\mathrm{CoCl}_{2}(100 \mu \mathrm{M})$ at 36 and $48 \mathrm{~h}$ with up-regulation of HIF-1 $\alpha$. The density of the CDX2 bands was quantified by densitometric analysis (C). Data are presented after normalization with the $\beta$-actin bands. ${ }^{*} \mathrm{p}<0.05,{ }^{* *} \mathrm{p}<0.01$ vs. normoxia.

To address this hypothesis, we performed in vitro experiments using colorectal cancer cell lines, SW480 and LS174T, cultured under normoxia and hypoxia mimicked by $\mathrm{CoCl}_{2}$. We analyzed the hypoxia-induced change in the expression of CDX2 at the mRNA and protein levels using real-time RT-PCR, and Western blotting. The results indicated that mimicked hypoxic conditions $(100 \mu \mathrm{M})$ for 24,36 , and $48 \mathrm{~h}$ reduce the expression of CDX2 mRNA and protein in SW480 and LS174T. Simultaneously, the expression of HIF-1 $\alpha$ mRNA and protein peaks at $24 \mathrm{~h}$ and remains elevated at $48 \mathrm{~h}$ in SW480 and LS174T. Accordingly, our in vivo and in vitro observations indicate that mimicked hypoxia downregulates the expression of CDX2 in colorectal cancer cells.

The accumulation of genetic mutations in cell regulatory pathways plays a role in the development of several forms of human cancer (25). The acquisition of epigenetic changes, particularly transcriptional silencing via aberrant promoter methylation, may also lead to the inactivation of a number of genes during neoplastic transformation (26). However, a low frequency of genetic alteration was found in the CDX2 gene in human CRC, and methylation of CDX2 was rare in primary colorectal adenocarcinoma neoplasms, suggesting that genetic alterations, such as somatic mutation or allelic loss and methylation, may not be a major cause of expression abnormalities and carcinogenesis (12,27-29). It has been reported that CDX2 inactivation in colon cancer resulted from defects in trans-acting pathways regulating CDX2 transcription (21). A subsequent study found that transcription repressors associated with EMT, in particular Snail, is stimulated in migrating Caco2/TC7 cells and can downregulate $\mathrm{CDX} 2$. These authors further showed that the $\mathrm{CDX} 2$ promoter harbors a canonical E-box (CAGCTG, 400 bp), which might serve as a binding site for Snail, but mutation of this site does not abolish repression by Snail (17). Therefore, our study focused on the expression of the transcriptional repressor Snail because Snail is a target gene for hypoxia (18). Our study showed that the expression of Snail mRNA was increased and achieved the peak at $24 \mathrm{~h}$ and remains elevated at $48 \mathrm{~h}$ in these two cell lines under mimicked hypoxic conditions. Along with up-regulation of Snail, the expression of CDX2 mRNA and protein was decreased under hypoxia in both colonic cancer cell lines studied. However, the concrete mechanism remained unknown.

Collectively, it is likely that Snail participates in the hypoxia-induced attenuation of the expression of CDX2 in colorectal cancer cells. These data suggest that hypoxia 
contributes to tumor progression by inactivating CDX2 via Snail in colorectal adenocarcinoma. Further studies should focus on concrete regulative mechanism between Snail and CDX2. HIF-1 $\alpha$-Snail-CDX2 systems may be possible candidates for molecular targeting in the future treatment of malignant colorectal tumors.

\section{Acknowledgements}

This study was supported by a grant from the National Natural Science Foundation of China (Grant serial number: 30672070, 30400430) and a Key Science and Technology Project of Shaanxi Province (Grant serial number: 2009K12$01)$.

\section{References}

1. Jemal A, Siegel R, Ward E, et al: Cancer statistics, 2007. CA Cancer J Clin 57: 43-66, 2007.

2. Diep CB, Kleivi K, Ribeiro FR, et al: The order of genetic events associated with colorectal cancer progression inferred from meta-analysis of copy number changes. Gene Chromosome Cancer 45: 31-41, 2006.

3. Brabletz T, Jung A, Spaderna S, et al: Migrating cancer stem cells, an integrated concept of malignant tumour progression. Nat Rev Cancer 5: 743-749, 2005.

4. Freund JN, Domon-Dell C, Kedinger M and Duluc I: The Cdx-1 and Cdx-2 homeobox genes in the intestine. Biochem Cell Biol 76: 957-969, 1998.

5. Suh E and Traber PG: An intestine-specific homeobox gene regulates proliferation and differentiation. Mol Cell Biol 16: 619-625, 1996

6. Bonhomme C, Duluc I, Martin E, et al: The Cdx2 homeobox gene has a tumour suppressor function in the distal colon in addition to a homeotic role during gut development. Gut 52: $1465-1471,2003$.

7. Aoki K, Tamai, Y, Horiike, S, et al: Colonic polyposis caused by mTOR-mediated chromosomal instability in Apc(+/Delta716) Cdx2(+/-) compound mutant mice. Nat Genet 35: 323-330, 2003.

8. Bakaris S, Cetinkaya A, Ezberci F and Ekerbicer H: Expression of homeodomain protein CDX2 in colorectal adenoma and adenocarcinoma. Histol Histopathol 23: 1043-1047, 2008.

9. Choi BJ, Kim CJ, Cho YG, et al: Altered expression of CDX2 in colorectal cancers. APMIS 114: 50-54, 2006.

10. Ee HC, Erler T, Bhathal PS, et al: Cdx-2 homeodomain protein expression in human and rat colorectal adenoma and carcinoma. Am J Pathol 147: 586-592, 1995.

11. Brabletz T, Spaderna S, Kolb J, et al: Downregulation of the homeodomain factor cdx 2 in colorectal cancer by collagen type I: an active role for the tumor environment in malignant tumor progression. Cancer Res 64: 6973-6977, 2004.
12. Yagi OK, Akiyama Y and Yuasa Y: Genomic structure and alterations of homeobox gene CDX2 in colorectal carcinomas. Br J Cancer 79: 440-444, 1999.

13. Semenza GL: Regulation of mammalian $\mathrm{O}_{2}$ homeostasis by hypoxia inducible factor 1 . Annu Rev Cell Dev Biol 15: 551-578, 1999

14. Ratcliffe PJ, O'Rourke JF, Maxwell PH and Pugh CW: Oxygen sensing, hypoxia-inducible factor-1 and the regulation of mammalian gene expression. J Exp Biol 201: 1153-1162, 1998.

15. Zhong H, Dc Marzo AM, Laughner E, et al: Overexpression of hypoxia-inducible factor 1 alpha in common human cancers and their metastases. Cancer Res 59: 5830-5835, 1999.

16. Talks KL, Turley H, Gatter KC, et al: The expression and distribution of the hypoxia-inducible factors HIF-1 alpha and HIF-2 alpha in normal human tissues, cancers, and tumor associated macrophages. Am J Pathol 157: 411-421, 2000.

17. Gross I, Duluc I, Benameur T, et al: The intestine-specific homeobox gene $\mathrm{Cdx} 2$ decreases mobility and antagonizes dissemination of colon cancer cells. Oncogene 27: 107-115, 2008.

18. Luo DC, Wang JX, Li J and Martin P: Snail is a target gene for HIF. FASEB 21: 814-817, 2007.

19. Sahlgren C, Gustafsson MV, Jin S, et al: Notch signaling mediates hypoxia-induced tumor cell migration and invasion. Proc Natl Acad Sci USA 105: 6392-6397, 2008.

20. Mallo GV, Soubeyran P, Lissitzky JC, et al: Expression of the $\mathrm{Cdx} 1$ and $\mathrm{Cdx} 2$ homeotic genes leads to reduced malignancy in colon cancer-derived cell. J Biol Chem 273: 14030-14036, 1998.

21. Hinoi T, Loda M and Fearon ER: Silencing of CDX2 expression in colon cancer via a dominant repression pathway. J Biol Chem 278: 44608-44616, 2003.

22. Kaimaktchiev V, Terracciano L, Tornillo L, et al: The homeobox intestinal differentiation factor CDX2 is selectively expressed in gastrointestinal adenocarcinomas. Mod Pathol 17: 1392-1399, 2004.

23. Benahmed F, Gross I, Guenot D, et al: The microenvironment controls CDX2 homeobox gene expression in colorectal cancer cells. Am J Pathol 170: 733-744, 2007.

24. Vukovic V, Haugland HK, Nicklee T, et al: Hypoxia- inducible factor- $1 \alpha$ is an intrinsic marker for hypoxia in cervical cancer xenografts. Cancer Res 61: 7394-7398, 2001.

25. Vogelstein B and Kinzler KW: The multistep nature of cancer. Trends Genet 9: 138-141, 1993.

26. Herman JG and Baylin SB: Gene silencing in cancer in association with promoter hypermethylation. N Engl J Med 349: 2042-2054, 2003.

27. Sivagnanasundaram S, Islam I, Talbot I, et al: The homeobox gene CDX2 in colorectal carcinoma: a genetic analysis. Br J Cancer 84: 218-225, 2001.

28. Guo M, House MG, Suzuki H, et al: Epigenetic silencing of CDX2 is a feature of squamous esophageal cancer. Int J Cancer 121: 1219-1226, 2007.

29. Pereira B, Oliveira C, David L, et al: CDX2 promoter methylation is not associated with mRNA expression. Int J Cancer 125: 1739-1742, 2009. 